\title{
Enhanced Quenching Effect of Neonicotinoid Pesticides on Time-Resolved Terbium Luminescence in Presence of Surfactants
}

\author{
A. Ruiz-Medina $(\mathbb{D}$, , M. I. Soler-Gallardo, and E. J. Llorent-Martínez $(\mathbb{D}$ \\ Department of Physical and Analytical Chemistry, Faculty of Experimental Sciences, University of Jaén, Campus Las Lagunillas, \\ E-23071 Jaén, Spain
}

Correspondence should be addressed to E. J. Llorent-Martínez; ellorent@ujaen.es

Received 30 September 2018; Accepted 12 November 2018; Published 2 December 2018

Academic Editor: Maurice Millet

Copyright (C) 2018 A. Ruiz-Medina et al. This is an open access article distributed under the Creative Commons Attribution License, which permits unrestricted use, distribution, and reproduction in any medium, provided the original work is properly cited.

\begin{abstract}
A luminescence analytical method for the quantification of neonicotinoid pesticides (acetamiprid, clothianidin, dinotefuran, imidacloprid, nitenpyram, thiacloprid, and thiamethoxam) in water samples is proposed. The method is based on the quenching effect that these analytes produce on the time-resolved luminescence signal of terbium ions (excitation/emission wavelengths of $256 / 545 \mathrm{~nm} / \mathrm{nm}$ ). An enhancement on the analytical signal is observed when surfactants are used in the system. The use of a $0.01 \mathrm{~mol} \cdot \mathrm{L}^{-1}$ sodium dodecyl sulfate produced approximately a $30 \%$ increase in the sensitivity of the method. Under the optimum conditions, the method presented detection limits between 0.03 and $0.23 \mu \mathrm{g} \cdot \mathrm{mL}^{-1}$. Interference studies were performed for ions commonly present in waters, observing no interferences. In addition, recovery experiments were performed in different waters, well, spring, and swamp, observing recovery yields close to $100 \%$, with relative standard deviations lower than $4 \%$ in all cases. No sample treatment except a filtration step was required. Hence, this method may represent an alternative to other existing methods for the quick and simple analysis of these ubiquitous insecticides in environmental waters.
\end{abstract}

\section{Introduction}

Neonicotinoids are broad-spectrum systemic insecticides that are used in hundreds of field crops throughout the world. The use of these insecticides has constantly grown since their appearance. In 1990, organophosphates dominated the market, but by 2008 , neonicotinoids already represented a $24 \%$ share of the pesticides market [1], and they still are the most abundant pesticides. Neonicotinoids are persistent, have high leaching and runoff potential, and are toxic to many invertebrates, hence representing a risk to surface waters, fauna, and ecosystems [2]. Five neonicotinoids are approved as active substances in the European Union (EU) for plant protection products: acetamiprid (AC), clothianidin (CL), imidacloprid (IM), thiacloprid (TH), and thiamethoxam (TX). On the other hand, dinotefuran (DF) and nitenpyram (NT), which are the most recent neonicotinoids, are not approved in the EU [3]. All neonicotinoids are potent agonists, acting selectively on insect nicotinic acetylcholine receptors [4].
Most of the concerns regarding the use of neonicotinoids are related to their harmful effects to bees, which also affect whole ecosystems [5]. Hence, the European Union prohibited the use of CL, IM, and TX on crops attractive to bees, and these chemicals will be banned on outdoor crops [6]. Although more controls have been demanded in crops, the use of neonicotinoids also derives in the contamination of environmental waters close to agricultural areas [7], which can produce adverse effects to additional nontarget species. For instance, the presence of residues of IM in surface waters in the Netherlands has been related to a decrease in the abundance of aquatic macroinvertebrate species [8]. This study was consistent with previous reports concerning the effects of neonicotinoids in aquatic invertebrates $[9,10]$. Therefore, it is important to control the levels of these pesticides not only in crops but also in environmental waters.

The most common approach for the quantification of neonicotinoids in water samples consists in their separation by liquid chromatography followed by mass spectrometry 
[11-13] or UV $[14,15]$ detection. The sample treatments vary between conventional liquid-liquid extraction [15], solid-phase extraction [11], on-line solid-phase extraction [13], and magnetic solid-phase extraction [14]. In addition, the analysis of neonicotinoids without sample treatment has also been reported [12]. Capillary electrophoresis with UV detection is another option after an off-line solid-phase extraction procedure $[16,17]$. For the quantification of selected neonicotinoids, immunoassays [18, 19], electrochemical methods [20-22], and photochemically induced fluorescence $[23,24]$ have also been employed after appropriate sample treatments.

In this work, we propose a novel luminescence method for the quantification of neonicotinoids in environmental waters. These pesticides do not present native fluorescence, so other alternatives are required for their luminescent determination. An interesting approach is the use of luminescence probes, recording the variation observed by the addition of the analytes. Here, we report the quenching produced by neonicotinoids on the luminescence signal of terbium. In analytical chemistry, the detection called terbium-sensitized luminescence (TSL) is based on the increase observed when terbium ions form complexes with fluorescence compounds [25]. However, in the method proposed here, the analytical signal is the quenching produced by the analytes on terbium ions. This method makes use of one of the most important advantages of TSL, the long luminescence lifetime of terbium luminescence, which allows performing time-resolved luminescence measurements, thus avoiding interference from fluorescence compounds [26]. In addition, we report the enhancement observed in the analytical signal when surfactants are used in the system. The analytical method proposed here was successfully applied to the individual quantitation of seven neonicotinoids in different environmental waters.

\section{Materials and Methods}

2.1. Reagents and Solutions. AC (99.9\%), CL (99.9\%), DF (99.6\%), IM (99.9\%), NT (99.6\%), TH (99.9\%), and TX (99.6\%) were obtained from Sigma-Aldrich (Madrid, Spain). Individual stock solutions of $100 \mu \mathrm{g} \cdot \mathrm{mL}^{-1}$ of each analyte were prepared in methanol (Sigma-Aldrich). The solutions were kept in the dark at $4^{\circ} \mathrm{C}$ and were stable for at least one month. Working solutions were prepared daily by appropriate dilution with ultrapure water (Milli-Q Waters purification system, Millipore, Milford, MA, USA). Terbium (III) nitrate pentahydrate (99.9\%), europium (III) nitrate pentahydrate, citric acid, sodium citrate, sodium acetate, acetic acid, cetyltrimethylammonium chloride, Triton X-100, sodium hydroxide, and hydrochloric acid were also purchased from Sigma-Aldrich, whereas sodium dodecyl sulfate (SDS) was obtained from Panreac (Barcelona, Spain).

2.2. Instrumentation and Apparatus. Luminescence measurements were recorded in a Cary Eclipse luminescence spectrometer (Varian Inc., Mulgrave, Australia) with Cary Eclipse (Varian) software and a Hellma 1010-QS quartz cuvette $(3500 \mu \mathrm{L}$ volume, $10 \times 10 \mathrm{~mm}$ light path $) . A \mathrm{pH}$ meter Crison GLP21 (Crison Instruments, Barcelona, Spain) was also used.

2.3. General Procedure. We prepared all solutions in $10 \mathrm{~mL}$ volumetric flasks, completing to volume with ultrapure water. All solutions had constant concentrations of $5 \times$ $10^{-4} \mathrm{~mol} \cdot \mathrm{L}^{-1} \cdot \mathrm{Tb}^{3+}$ and $0.01 \mathrm{~mol} \cdot \mathrm{L}^{-1} \mathrm{SDS}$, prepared in acetate buffer $0.05 \mathrm{~mol} \cdot \mathrm{L}^{-1}, \mathrm{pH}$ 5.5. The calibration graphs were prepared in the linear dynamic ranges and are shown in Table 1. Emission luminescence spectra were recorded at an excitation wavelength of $256 \mathrm{~nm}$, and the peak height of $545 \mathrm{~nm}$ was measured. The quenching observed in the analytical signal by the addition of each analyte was the analytical signal (terbium signal minus terbium + analyte signal). Hence, a terbium blank solution was always recorded. The instrumental conditions were excitation and emission slit widths, $20 / 20 \mathrm{~nm} / \mathrm{nm}$; photomultiplier voltage, $750 \mathrm{~V}$; delay time, $0.1 \mathrm{~ms}$; gate time, $3 \mathrm{~ms}$. All standard and sample solutions were analyzed in triplicate.

\section{Results and Discussion}

Neonicotinoids are nonfluorescent or slightly fluorescent compounds. Hence, native fluorescence cannot be measured, and photochemically induced fluorescence is the most usual detection technique for their spectroscopic quantification. However, we observed that neonicotinoids produce a quenching effect on the time-resolved luminescence of lanthanide ions. The quenching was proportional to the analyte concentration (each analyte was tested individually), so the instrumental and chemical variables were optimized to obtain the highest sensitivity. The use of terbium instead of europium resulted in approximately a 30-50\% enhancement in the analytical signal, so terbium ions were used for further experiments.

3.1. Instrumental Variables. The usual approach for analytical methods based on terbium luminescence consists in the use of terbium-sensitized luminescence (TSL). However, TSL is suitable for fluorescence compounds that form complexes with terbium ions, increasing the luminescence intensity. The detection proposed here is based on the opposite effect: the quenching of terbium luminescence by the analytes. Therefore, both excitation and emission wavelengths corresponded to terbium, resulting in optimum excitation/emission wavelengths of $256 / 545 \mathrm{~nm} / \mathrm{nm}$.

The luminescence signal was recorded in the timeresolved mode. We thus optimized the delay $(0.1-0.3 \mathrm{~ms})$ and gate $(1-5 \mathrm{~ms})$ times. The analytical signal decreased as the delay time increased, so we set it at $0.1 \mathrm{~ms}$. On the other hand, the analytical signal increased up to $3 \mathrm{~ms}$ of gate time, which was the selected value.

Finally, the effect of the excitation/emission slit widths $(5-20 \mathrm{~nm})$ and the voltage of the photomultiplier tube detector (400-800 V) were studied. Taking into account that the analytical signal corresponded to the quenching produced by the analyte on terbium ions, these parameters were optimized to obtain the highest terbium signal (blank signal) 
TABLe 1: Analytical parameters for all the studied analytes.

\begin{tabular}{|c|c|c|c|c|c|c|c|}
\hline Parameter & $\mathrm{AC}$ & $\mathrm{CL}$ & DF & IM & NT & $\mathrm{TH}$ & TX \\
\hline \multicolumn{8}{|l|}{ Calibration graph } \\
\hline Intercept & 20.91 & 14.35 & 17.38 & 20.11 & 12.54 & 13.68 & 21.92 \\
\hline Slope $\left(\mathrm{mL} \mu \mathrm{g}^{-1}\right)$ & 96.64 & 30.06 & 91.37 & 44.26 & 83.41 & 62.57 & 148.03 \\
\hline Correlation coefficient & 0.9910 & 0.9965 & 0.9927 & 0.9925 & 0.9915 & 0.9927 & 0.9962 \\
\hline Linear dynamic range $\left(\mu \mathrm{g} \mathrm{mL}^{-1}\right)$ & $0.2-8$ & $0.75-15$ & $0.33-9$ & $0.75-8$ & $0.2-10$ & $0.2-7$ & $0.1-5$ \\
\hline Detection limit $\left(\mu \mathrm{g} \mathrm{mL}^{-1}\right)$ & 0.06 & 0.23 & 0.10 & 0.23 & 0.06 & 0.06 & 0.03 \\
\hline Quantitation limit $\left(\mu \mathrm{g} \mathrm{mL}^{-1}\right)$ & 0.20 & 0.75 & 0.33 & 0.75 & 0.20 & 0.20 & 0.10 \\
\hline Repeatability $(\%)^{\mathrm{a}}$ & 2.54 & 2.23 & 3.15 & 3.54 & 3.45 & 2.19 & 3.23 \\
\hline Intermediate precision $(\%)^{\mathrm{b}}$ & 3.87 & 3.95 & 4.56 & 4.85 & 4.22 & 3.72 & 4.35 \\
\hline
\end{tabular}

AC, acetamiprid; CL, clothianidin; DF, dinotefuran; IM, imidacloprid; NT, nitenpyram; TH, thiacloprid; TX, thiamethoxam. ${ }^{\mathrm{a}} n=10$; ${ }^{\mathrm{b}} n=10 ; 3$ consecutive days.

to improve both sensitivity and linear dynamic range. The highest the terbium blank signal, the highest the sensitivity of the system. The highest analytical signal was obtained for excitation/emission slit widths of $20 / 20 \mathrm{~nm} / \mathrm{nm}$ and a photomultiplier voltage of $770 \mathrm{~V}$.

3.2. Chemical Variables. The $\mathrm{pH}$ value, as well as terbium and surfactant concentrations, was optimized in this section. First, the $\mathrm{pH}$ of the sample or standard solutions is a critical parameter, affecting the interaction between terbium ions and the analytes. We studied the influence of the $\mathrm{pH}$ between 3.0 and 8.0, adjusting the $\mathrm{pH}$ of solutions with $\mathrm{NaOH}$ or $\mathrm{HCl}$. In most of the terbium-based luminescence analytical methods, the use of a $\mathrm{pH}$ value in the range 5.0-6.0 produces the highest analytical signal. In this work, $\mathrm{pH}$ values between 4.5 and 6.0 also produced the highest sensitivity. There was no quenching for $\mathrm{pH}$ values lower than 4.0 , whereas the use of $\mathrm{pH}$ values higher than 7.5 produced terbium hydrolysis and could not be used. Hence, we tested the influence of two buffer solutions (acetate and citrate) in the optimum $\mathrm{pH}$ range, obtaining the best results for an acetate/acetic acid buffer solution at $\mathrm{pH} 5.5$ and a concentration of $0.05 \mathrm{~mol} \cdot \mathrm{L}^{-1}$.

Secondly, we optimized terbium concentration, which was a critical parameter. The effect of terbium was studied for concentrations between $10^{-5}$ and $10^{-3} \mathrm{~mol} \cdot \mathrm{L}^{-1}$. The signal increased proportionally to terbium concentration up to a value of $5 \times 10^{-4} \mathrm{~mol} \cdot \mathrm{L}^{-1}$, which was chosen as optimum for all the analytes (higher terbium concentrations did not improve the analytical signal).

Finally, we studied the influence of different surfactants, cetyltrimethylammonium chloride, SDS, and Triton X-100, on the analytical signal. The use of surfactants is common in TSL, as they can cancel the quenching of coordinated water molecules and protect the chelate against nonradiative processes [25]. In this case, we measure the quenching of the signal; hence, it is important to avoid other deactivating mechanisms in the luminescence signal. Of the studied surfactants, only SDS produced an improvement on the analytical signal. This is probably due to the interaction between terbium and SDS micelles, whereas no interaction with the other micelles took place. The effect of SDS concentration was tested between 0.001 and $0.015 \mathrm{~mol} \cdot \mathrm{L}^{-1}$, obtaining the best signal at a $0.01 \mathrm{~mol} \cdot \mathrm{L}^{-1}$ SDS concentration for all the analytes (Figure 1), the enhancement depended on the analyte structure and,

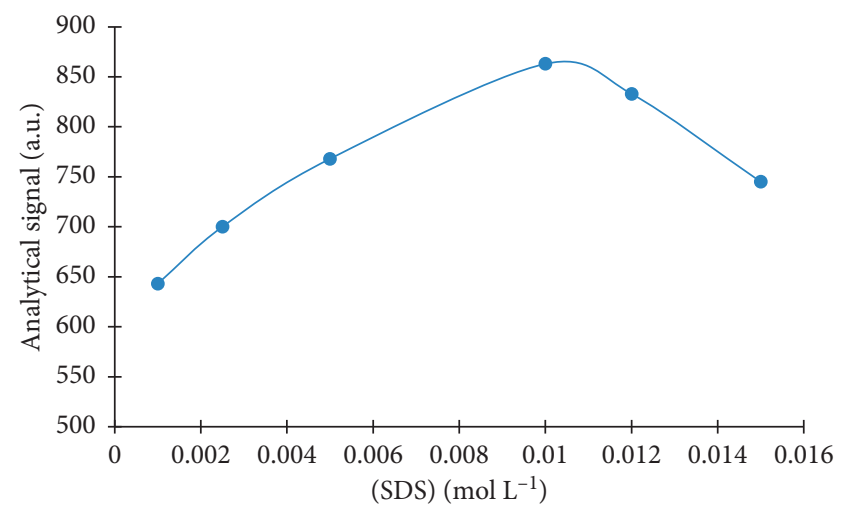

Figure 1: Effect of sodium dodecyl sulfate on the analytical signal for $10 \mathrm{mg} \cdot \mathrm{L}^{-1}$ nitenpyram.

consequently, on its potential to interact with the terbium-SDS system. As it can be observed in Figure 2, NT sensitivity was highly improved (more than 50\% enhancement), whereas CL signal was barely affected. However, improvements around $30 \%$ were observed for most of the analytes.

We evaluated the quenching mechanism through the Stern-Volmer equation. This equation is applicable if the experimental results show linear variation, which was not the case for the target analytes. We observed a positive variation of the linearity, hence indicating that the quenching mechanism is not only collisional [27].

3.3. InterferenceStudy. We studied the potential interference of different ions that can be present in environmental waters. This study was carried out for $1 \mu \mathrm{g} \cdot \mathrm{mL}^{-1}$ for each analyte, observing similar results in all cases. The tolerance level was defined as the level of foreign species that produced an error lower than $\pm 4 \%$ (the usual repeatability) in the determination of the analytes. As an example, the results obtained for NT are shown in Table 2. The tolerances observed indicate that these analytes could be quantified in the target samples (Figure 3) without interferences from other inorganic ions, although a sample treatment would be required for sea water or some groundwaters that may present higher ions concentrations. In addition, time-resolved luminescence is used as detection technique. Hence, other coexisting fluorescent pesticides would not interfere due to 


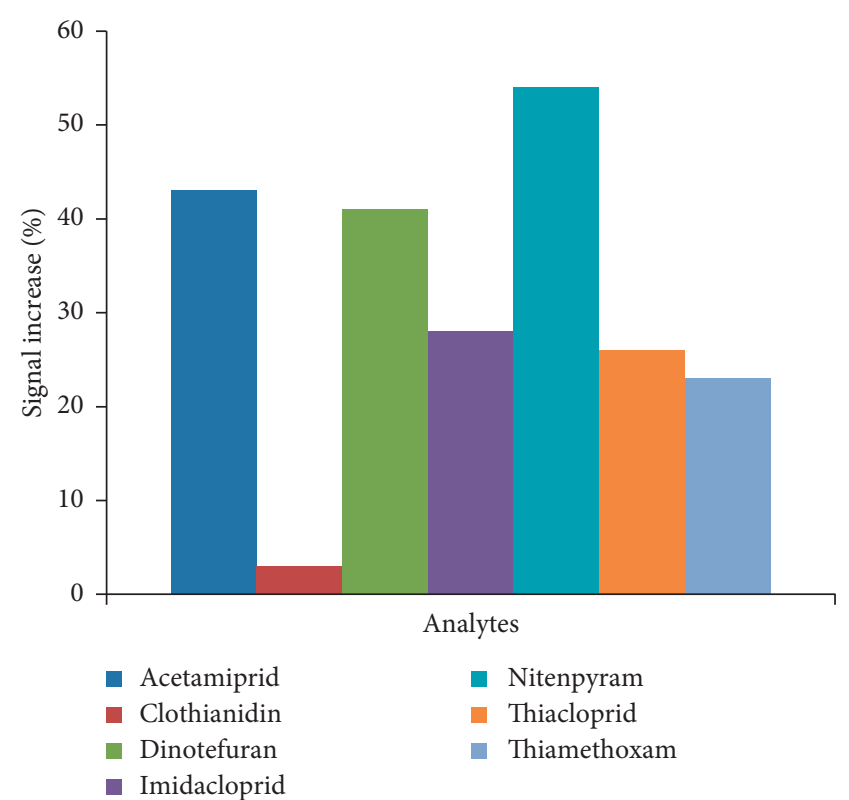

Figure 2: Signal increase, in percentage, when sodium dodecyl sulfate was used compared to the absence of the surfactant.

TABLE 2: Interference study carried out for $1 \mu \mathrm{g} \cdot \mathrm{mL}^{-1} \cdot \mathrm{NT}$.

\begin{tabular}{lc}
\hline Foreign species & $\begin{array}{c}\text { Tolerated interferent/analyte }(\mathrm{w} / \mathrm{w}) \\
\text { ratio }\end{array}$ \\
\hline $\mathrm{CO}_{3}^{2-}$ & $100^{\mathrm{a}}$ \\
$\mathrm{Ca}^{2+}, \mathrm{Cl}^{-}, \mathrm{K}^{+}, \mathrm{Mg}^{2+}$, and & $20^{\mathrm{a}}$ \\
$\mathrm{PO}_{4}{ }^{3-}$ & 10 \\
$\mathrm{Na}^{+}, \mathrm{NO}^{3-}$, and $\mathrm{CN}^{-}$ & 5 \\
$\mathrm{Cr}^{3+}$ and $\mathrm{Cu}^{2+}$ & \\
\hline
\end{tabular}

${ }^{a}$ Maximum ratio tested.

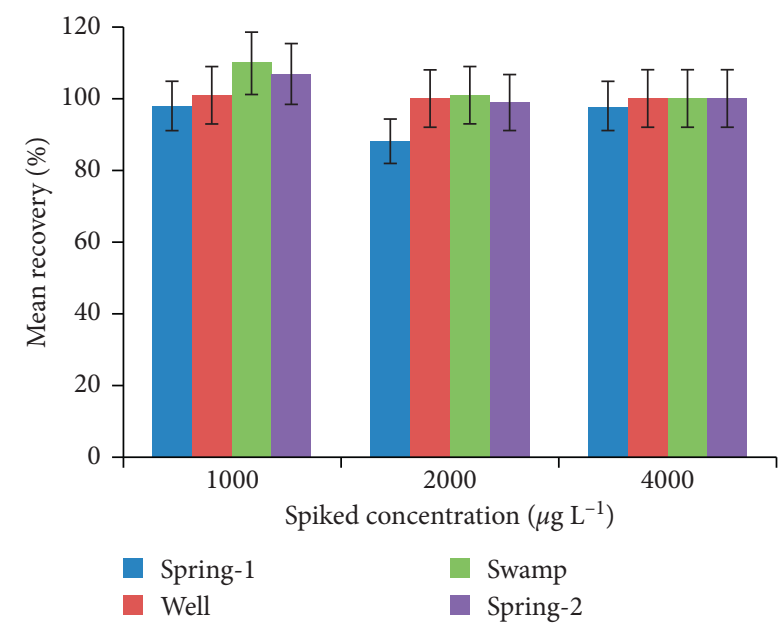

FIGURE 3: Mean recovery (average of all the analytes) for each water sample at three different spiked levels.

the time-resolved mode employed, which avoids the recording of fluorescent background signals.

3.4. Figures of Merit. The analytical parameters of the method were studied under the optimum conditions previously described. Although chemical and instrumental variables were the same for all the analytes, differences were observed in terms of sensitivity. Figures of merits are shown in Table 1 for all the analytes.

The calibration graphs were constructed fitting the data by standard least-squares treatment, whereas detection and quantitation limits were calculated by the $3 \sigma$ and $10 \sigma$ criteria. The lowest detection limit was obtained for TX $\left(0.03 \mu \mathrm{g} \cdot \mathrm{mL}^{-1}\right)$, whereas the highest detection limits corresponded to CL and IM $\left(0.23 \mu \mathrm{g} \cdot \mathrm{mL}^{-1}\right)$. Repeatability was lower than $4 \%$, whereas intermediate precision (3 consecutive days) was lower than $5 \%$ in all cases.

The robustness of the method was also evaluated by performing small variations in instrumental variables $( \pm 2 \mathrm{~nm}$ in excitation/emission wavelengths; $\pm 10 \mathrm{~V}$ in photomultiplier tube) and chemical variables $( \pm 5 \%$ variation in terbium, buffer, and SDS concentrations). In all cases, the variations of the analytical signal were lower than $4 \%$ compared to the optimum conditions.

3.5. Analytical Applications. The method developed was applied to the determination of neonicotinoids in environmental water samples: spring, swamp, and well. Four samples, located in different locations in the province of Jaén (South of Spain), were selected. First, all samples were analyzed (after filtration to eliminate particulate matter) to ensure the absence of the analytes. Taking into account that neither of the analytes was present in the selected samples, we performed recovery experiments in all samples. Each sample was spiked with each analyte at three different concentrations (1000, 2000, and $4000 \mu \mathrm{g} \cdot \mathrm{L}^{-1}$ ). No matrix effect was observed, so we used external calibration. Taking into account that four water samples were spiked with six analytes at three concentration levels, the average results obtained for all the analytes at each concentration are shown in Figure 3 to summarize the results. In all cases, recoveries between 90 and $110 \%$ and relative standard deviations $(n=3)$ lower than $4 \%$ were obtained. To evaluate the accuracy of the method, we used the method of the average recovery [28], which demonstrated the accuracy of the analytical method.

\section{Conclusions}

In this work, we report a novel analytical method for the quantitation of neonicotinoid insecticides. The method is based on the quenching effect produced by the target analytes on the luminescence signal of terbium ions. The use of time-resolved luminescence permits to avoid interferences from other potentially present fluorescence compounds. In addition, the enhancement produced in the analytical signal by the use of the surfactant SDS has been reported. We validated the accuracy of the method by recovery experiments in four environmental waters, obtaining recovery yields close to $100 \%$ in all cases. Hence, this method may represent a simple and rapid alternative to other existing methods, although positive results would have to be 
analyzed by liquid chromatography to assess the exact identity of the neonicotinoid pesticide detected.

\section{Data Availability}

The data used to support the findings of this study are available from the corresponding author upon request.

\section{Conflicts of Interest}

The authors declare that there are no conflicts of interest regarding the publication of this paper.

\section{Acknowledgments}

This study was funded by the "Ministerio de Economía y Competitividad" (grant number CTQ2016-7511-R).

\section{References}

[1] P. Jeschke, R. Nauen, M. Schindler, and A. Elbert, "Overview of the status and global strategy for neonicotinoids," Journal of Agricultural and Food Chemistry, vol. 59, no. 7, pp. 28972908, 2011.

[2] C. A. Morrissey, P. Mineau, J. H. Devries et al., "Neonicotinoid contamination of global surface waters and associated risk to aquatic invertebrates: a review," Environment International, vol. 74, pp. 291-303, 2015.

[3] E. Comission, http://ec.europa.eu/food/plant/pesticides/eupesticides-database.

[4] P. Jeschke and R. Nauen, "Neonicotinoids-from zero to hero in insecticide chemistry," Pest Management Science, vol. 64, no. 11, pp. 1084-1098, 2008.

[5] T. Blacquière, G. Smagghe, C. A. M. van Gestel, and V. Mommaerts, "Neonicotinoids in bees: a review on concentrations, side-effects and risk assessment," Ecotoxicology, vol. 21, no. 4, pp. 973-992, 2012.

[6] D. Butler, "EU expected to vote on pesticide ban after major scientific review," Nature, vol. 555, no. 7695, pp. 150-151, 2018.

[7] K. Starner and K. S. Goh, "Detections of the neonicotinoid insecticide imidacloprid in surface waters of three agricultural Regions of California, USA, 2010-2011," Bulletin of Environmental Contamination and Toxicology, vol. 88, no. 3, pp. 316-321, 2012.

[8] T. C. Van Dijk, M. A. Van Staalduinen, and J. P. Van der Sluijs, "Macro-invertebrate decline in surface water polluted with imidacloprid," PLoS One, vol. 8, no. 5, Article ID e62374, 2013.

[9] S. J. Stoughton, K. Liber, J. Culp, and A. Cessna, "Acute and chronic toxicity of imidacloprid to the aquatic invertebrates chironomus tentans and hyalella azteca under constant- and pulse-exposure conditions," Archives of Environmental Contamination and Toxicology, vol. 54, no. 4, pp. 662-673, 2008.

[10] A. M. Sardo and A. M. V. M. Soares, "Assessment of the effects of the pesticide imidacloprid on the behaviour of the aquatic oligochaete lumbriculus variegatus," Archives of Environmental Contamination and Toxicology, vol. 58, no. 3, pp. 648-656, 2010.

[11] N. Dujaković, S. Grujić, M. Radišić, T. Vasiljević, and M. Laušević, "Determination of pesticides in surface and ground waters by liquid chromatography-electrospray- tandem mass spectrometry," Analytica Chimica Acta, vol. 678, no. 1, pp. 63-72, 2010.

[12] V. G. Amelin, D. S. Bol'shakov, and A. M. Andoralov, "Screening and determination of pesticides from various classes in natural water without sample preparation by ultra HPLC-high-resolution quadrupole time-of-flight mass spectrometry," Journal of Analytical Chemistry, vol. 73, no. 3, pp. 257-265, 2018.

[13] J. M. Montiel-León, S. V. Duy, G. Munoz, M. Amyot, and S. Sauvé, "Evaluation of on-line concentration coupled to liquid chromatography tandem mass spectrometry for the quantification of neonicotinoids and fipronil in surface water and tap water," Analytical and Bioanalytical Chemistry, vol. 410, no. 11, pp. 2765-2779, 2018.

[14] V. Moreno, E. J. Llorent-Martínez, M. Zougagh, and A. Ríos, "Synthesis of hybrid magnetic carbon nanotubes-C18modified nano $\mathrm{SiO}_{2}$ under supercritical carbon dioxide media and their analytical potential for solid-phase extraction of pesticides," Journal of Supercritical Fluids, vol. 137, pp. 66-73, 2018.

[15] V. G. Amelin, D. S. Bol'shakov, and A. V. Tretiakov, "Identification and determination of synthetic pyrethroids, chlorpyriphos, and neonicotinoids in water by gas and liquid chromatography," Journal of Analytical Chemistry, vol. 67, no. 4, pp. 354-359, 2012.

[16] G. Ettiene, R. Bauza, M. R. Plata, A. M. Contento, and Á. Ríos, "Determination of neonicotinoid insecticides in environmental samples by micellar electrokinetic chromatography using solid-phase treatments," Electrophoresis, vol. 33, no. 1920, pp. 2969-2977, 2012.

[17] V. G. Amelin, D. S. Bol'shakov, and A. V. Tretyakov, "Separation and quantification of polar pesticides in well, surface, and drinking water by capillary electrophoresis," Journal of Analytical Chemistry, vol. 67, no. 11, pp. 904-924, 2012.

[18] X. Hua, Y. Ding, J. Yang, M. Ma, H. Shi, and M. Wang, "Direct competitive fluoroimmunoassays for detection of imidaclothiz in environmental and agricultural samples using quantum dots and europium as labels," Science of The Total Environment, vol. 583, pp. 222-227, 2017.

[19] F. Si, R. Zou, S. Jiao, X. Qiao, Y. Guo, and G. Zhu, "Inner filter effect-based homogeneous immunoassay for rapid detection of imidacloprid residue in environmental and food samples," Ecotoxicology and Environmental Safety, vol. 148, pp. 862$868,2018$.

[20] N. Lezi and A. Economou, "Voltammetric Determination of Neonicotinoid Pesticides at Disposable Screen-Printed Sensors Featuring a Sputtered Bismuth Electrode," Electroanalysis, vol. 27, no. 10, pp. 2313-2321, 2015.

[21] S. M. Taghdisi, N. M. Danesh, M. Ramezani, and K. Abnous, "Electrochemical aptamer based assay for the neonicotinoid insecticide acetamiprid based on the use of an unmodified gold electrode," Microchimica Acta, vol. 184, no. 2, pp. 499$505,2017$.

[22] V. Urbanová, A. Bakandritsos, P. Jakubec, T. Szambó, and R. Zbořil, "A facile graphene oxide based sensor for electrochemical detection of neonicotinoids," Biosensors and Bioelectronics, vol. 89, pp. 532-537, 2017.

[23] J. Jiménez-López, P. Ortega-Barrales, and A. Ruiz-Medina, "Determination of clothianidin in food products by using an automated system with photochemically induced fluorescence detection," Journal of Food Composition and Analysis, vol. 49, pp. 49-56, 2016.

[24] E. Fuentes, C. Cid, and M. E. Báez, "Determination of imidacloprid in water samples via photochemically induced 
fluorescence and second-order multivariate calibration," Talanta, vol. 134, pp. 8-15, 2015.

[25] A. Gómez-Hens and M. Aguilar-Caballos, "Terbiumsensitized luminescence: a selective and versatile analytical approach," TrAC Trends in Analytical Chemistry, vol. 21, no. 2, pp. 131-141, 2002.

[26] E. J. Llorent-Martínez, L. Molina-García, G. M. Durán, A. Ruiz-Medina, and Á. Ríos, "Direct determination of graphene quantum dots based on terbium-sensitized luminescence," Spectrochimica Acta Part A: Molecular and Biomolecular Spectroscopy, vol. 198, pp. 177-181, 2018.

[27] R. M. Melavanki, R. A. Kusanur, J. S. Kadadevaramath, and M. V. Kulakarni, "Quenching mechanisms of 5BAMC by aniline in different solvents using Stern-Volmer plots," Journal of Luminescence, vol. 129, no. 11, pp. 1298-1303, 2009.

[28] A. G. González, M. A. Herrador, and A. G. Asuero, "Intralaboratory testing of method accuracy from recovery assays," Talanta, vol. 48, no. 3, pp. 729-736, 1999. 

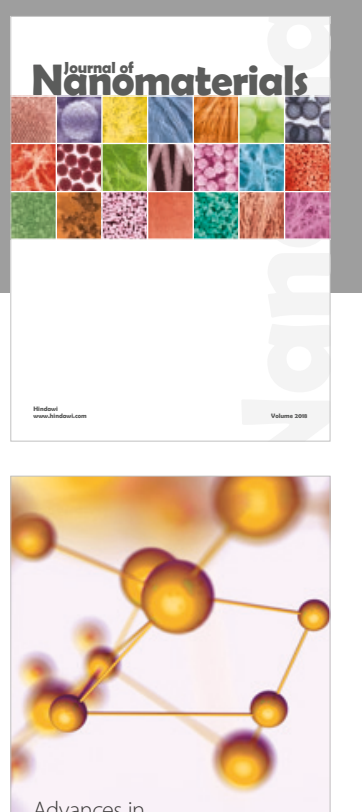

Physical Chemistry
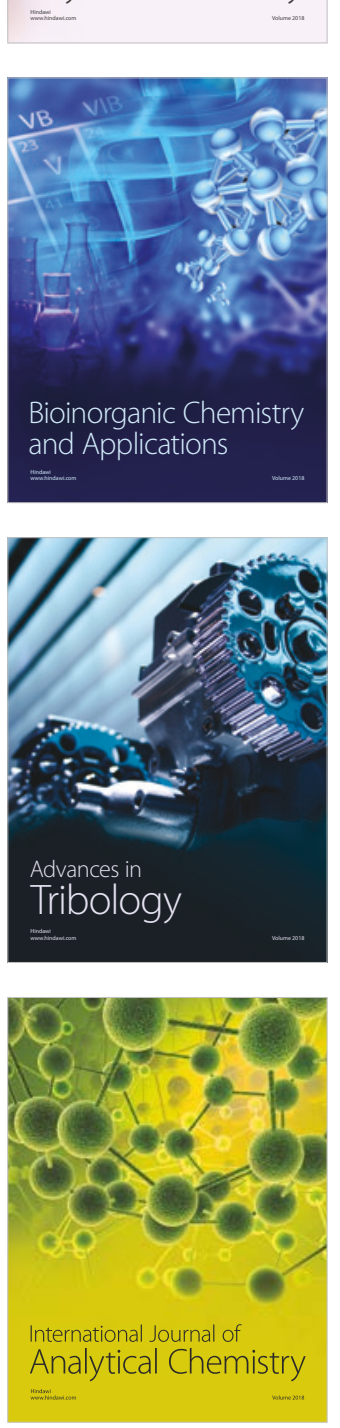

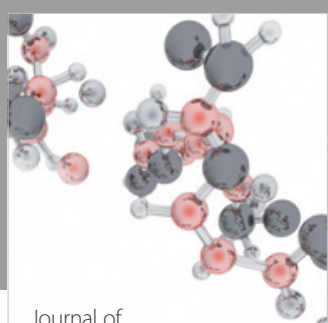

Analytical Methods

in Chemistry

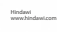

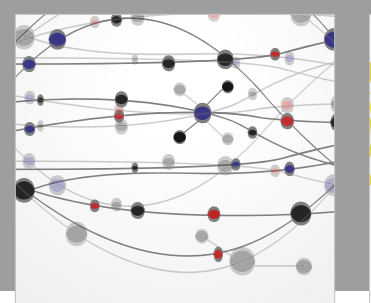

The Scientific World Journal

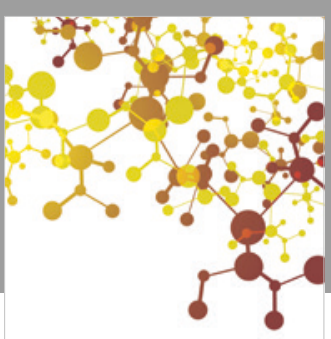

Journal of

Applied Chemistry
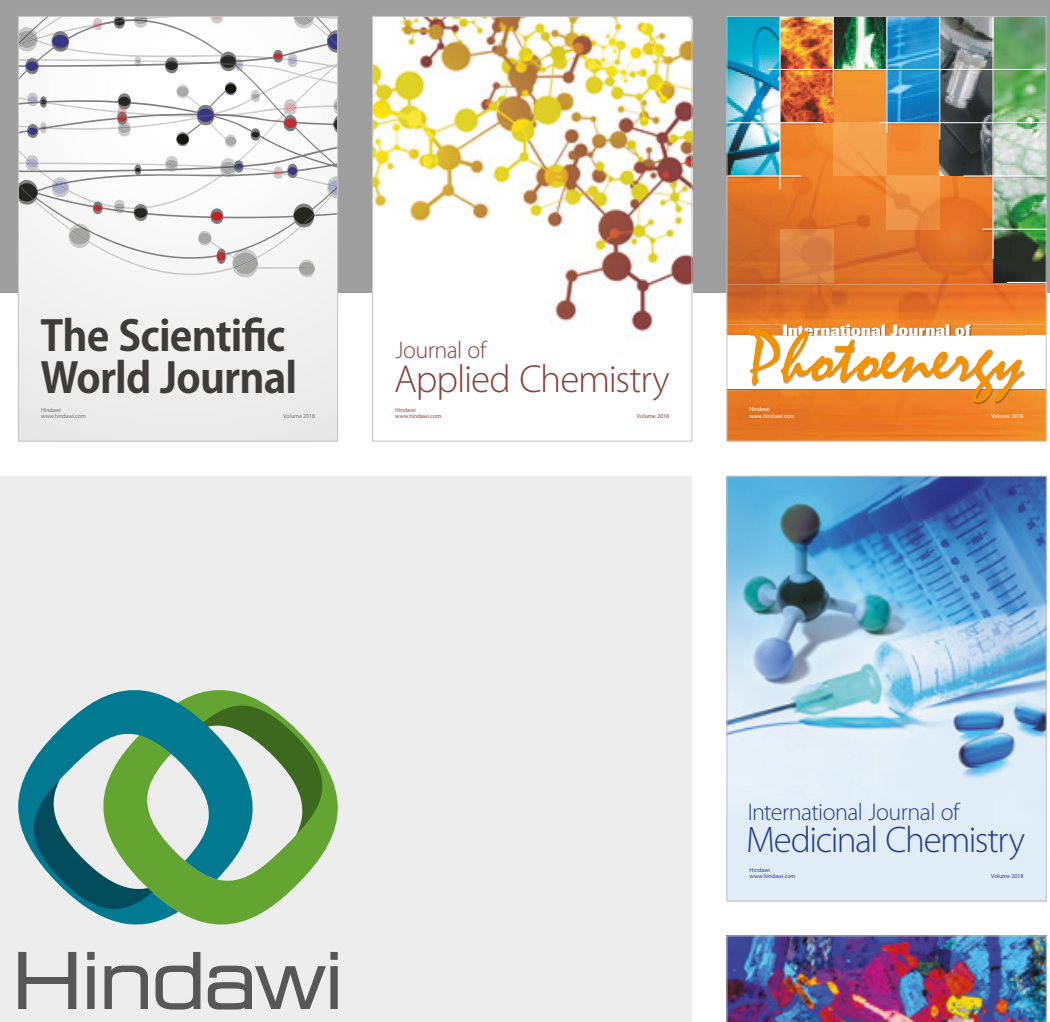

Submit your manuscripts at

www.hindawi.com
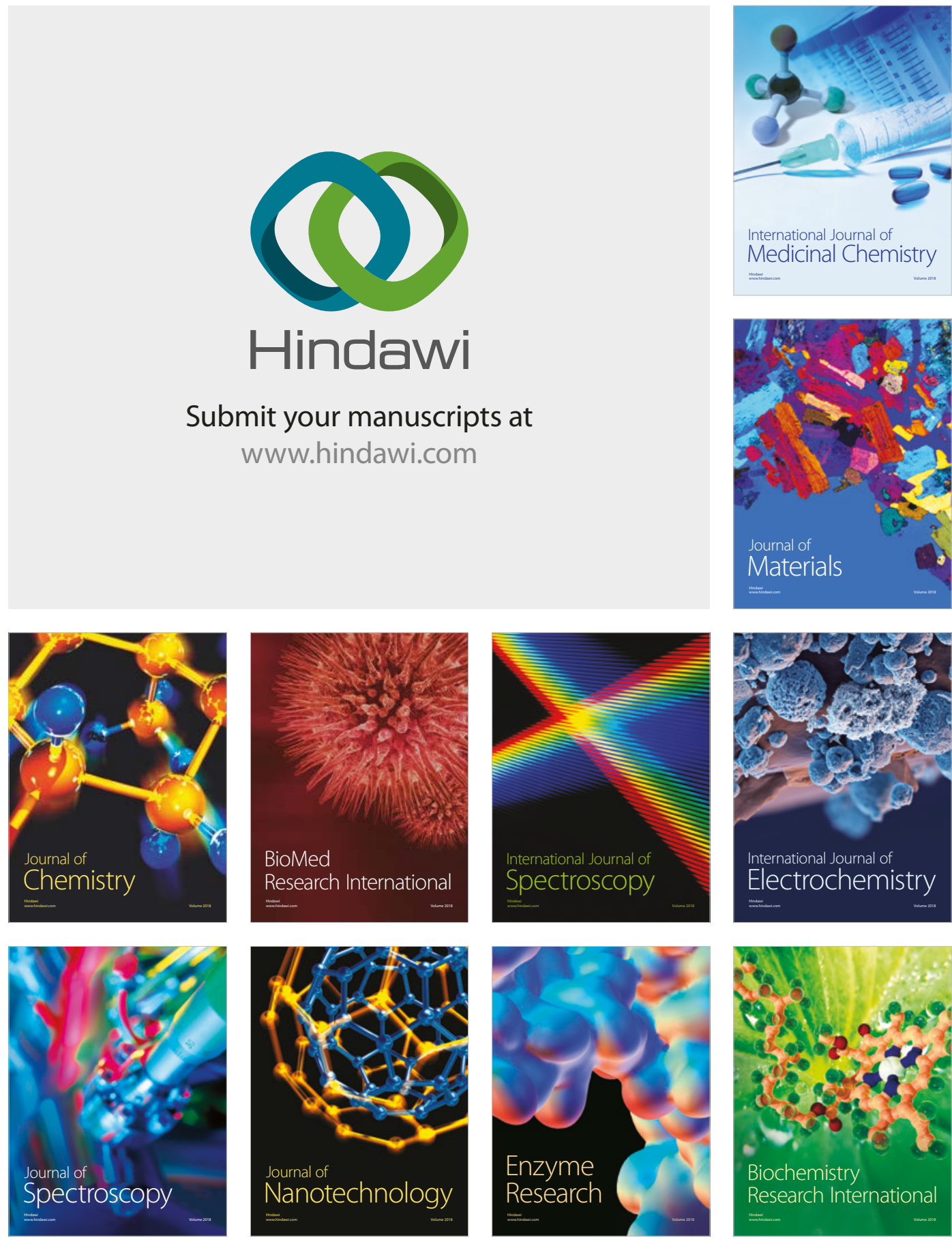
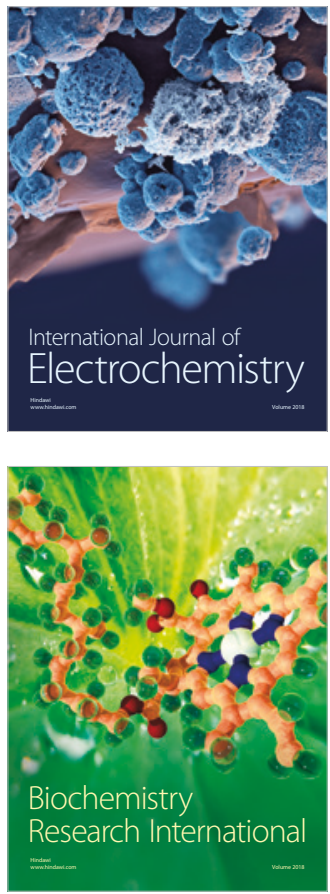